\title{
Interstitial deletion of chromosome 13: prognosis and adult phenotype
}

\author{
J C S Dean, S Simpson, D A Couzin, G S Stephen
}

\begin{abstract}
A de novo interstitial deletion of chromosome 13 $(46, X Y, \operatorname{del}(13)($ pter $\rightarrow$ q14.3::q22.3 $\rightarrow$ qter) $)$ is described in a 22 year old man with severe mental retardation, poor language development, low set ears, hypertelorism, broad nasal bridge, short hands and fingers, and a history of swallowing disorder in childhood with subsequent dyspepsia. The dysmorphic features did not become evident until later childhood, supporting the view that karyotyping should be performed routinely in all children with developmental delay.
\end{abstract}

A wide spectrum of abnormalities has been reported in association with deletions of the long arm of chromosome 13. ${ }^{1}$ Apart from the association of retinoblastoma with $13 \mathrm{q} 14$ deletion, ${ }^{2}$ assignment of other phenotypic abnormalities to proximal or distal $13 \mathrm{q}$ deletions has remained controversial.

We report a 22 year old patient with an interstitial deletion of chromosome 13 involving only bands q21 and $\mathrm{q} 22$, in order to delineate further the prognosis into adult life and the karyotype-phenotype correlations for this deletion.

\section{Case report}

The proband was delivered vaginally after induction at 41 weeks' gestation for postmaturity and low maternal oestriol. His birth weight was on the 10th centile and he was hypotonic with a shrill cry, but no dysmorphic features were noted.

At 5 months, he was referred for assessment of 'poor head control' and was found to be developmentally delayed. At 14 months, he required admission to hospital for bronchopneumonia associated with swallowing difficulties. At the age of 2 years, he had

Medical Genetics, Department of Molecular and Cell Biology, University of Aberdeen, Medical School, Foresterhill, Aberdeen AB9 2ZD.

J C S Dean, S Simpson, D A Couzin, G S Stephen Correspondence to Dr Dean.

Received for publication 28 December 1990. Accepted for publication 31 December 1990. global developmental delay, equivalent to a chronological age of 6 months. He had no speech until 5 years, when he was able to say " $\mathrm{Ma} \mathrm{Ma"} \mathrm{and} \mathrm{"} \mathrm{Ba} \mathrm{Ba"}$ and there has been no subsequent progress.

From 11 to 14 years, he had eight episodes of minor haematemesis, and barium meal showed a deformed duodenal cap suggestive of peptic ulcer disease.

Now aged 22 years, he is profoundly retarded and, although usually continent and able to dress himself, he requires constant supervision.

Physical examination showed short stature with distal limb shortening and brachydactyly. He has coarse facial features (fig 1) with strabismus, downward slanting eyes, and apparent hypertelorism (the inner canthal distance is on the 90th centile). He has a high arched palate, irregular dentition, and moderate gingivitis.

\section{FAMILY HISTORY}

His mother had had two previous stillbirths and two healthy children. The first stillbirth was a breech presentation at 37 weeks' gestation, whose birth weight was on the 10th centile. No external abnormalities were recorded. The second stillbirth was an induced vertex delivery at 41 weeks. There was meconium stained liquor and placental calcification. At necropsy, birth weight was on the 50th centile and no anatomical abnormalities were found.

\section{CYTOGENETICS}

Chromosome analysis on $\mathbf{G}$ banded metaphase spreads from PHA stimulated peripheral lymphocyte cultures after thymidine blocking showed a male karyotype with 46 chromosomes including a deleted 13. The abnormal chromosome appeared to be lacking the whole of band q21 and most, if not all, of band q22 (fig 2).

Although the precise localisation of breakpoints in an interstitial deletion is difficult, it is suggested that the proband has the karyotype 46,XY, del(13)(pter $\rightarrow$ q14.3::q22.3 $\rightarrow$ qter). Both parents and the proband's phenotypically normal sister have normal karyotypes.

Unfortunately, a cell line is not available from this patient. 

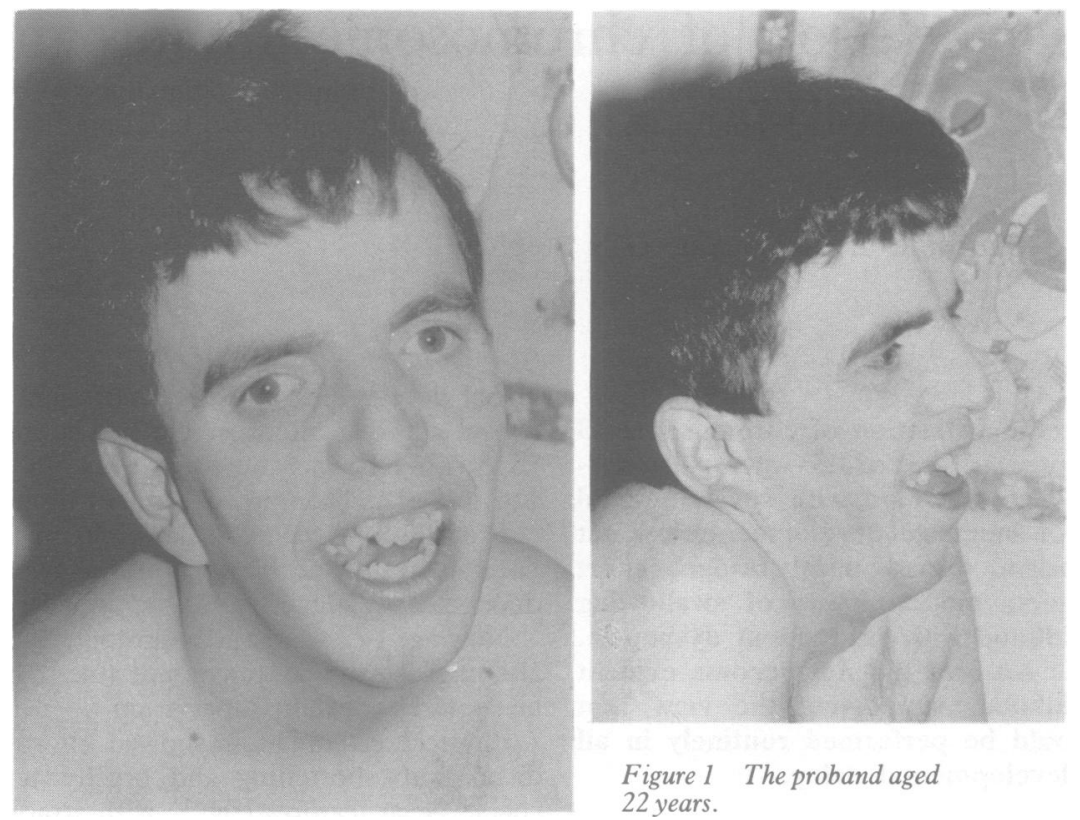

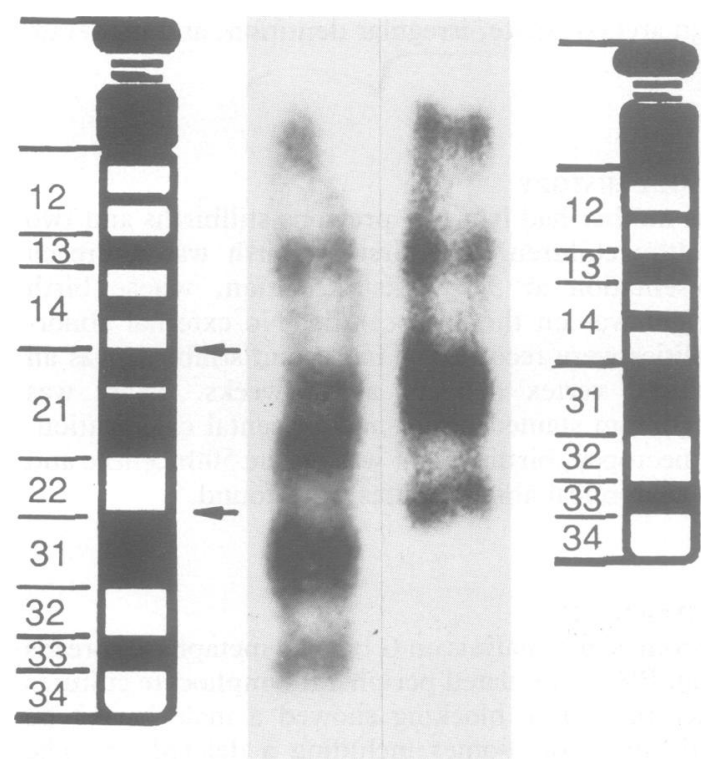

Figure 2 Idiograms of the normal and deleted chromosome 13 with the corresponding partial karyotypes. Arrows delineate the deleted region.

\section{Discussion}

This family is only the fourth reported in which a deletion of chromosome 13 limited to bands q21-22 has been found. In one family, a balanced interstitial translocation was found and two subjects carried the deletion. ${ }^{3}$ In the second, no family details were available, ${ }^{4}$ while in the third the deletion arose de novo. ${ }^{5}$ Our patient is the oldest described in detail, and represents the second apparent de novo deletion of this region.

None of these cases was ascertained at birth, but presented with delayed development, particularly of language acquisition. Dysmorphic features were not apparent initially, but became evident in later childhood, emphasising the need for routine karyotyping of all cases of delayed development of unknown aetiology.

Obstetric causes may have resulted in the stillbirths of two of our patient's sibs, but as karyotyping was not performed on these infants, gonadal mosaicism cannot be excluded.

The cardinal phenotypic features associated with 13q21-22 deletion include mental retardation, delayed language acquisition, postnatal growth retardation, short hands, low set or posteriorly rotated ears, and a broad nasal bridge. This phenotype is remarkably constant throughout the five cases reported (table). Strabismus and microcephaly occurred in three cases and in those with microcephaly the ears appeared relatively large. Swallowing difficulties with associated respiratory infections may also be prominent in early childhood, and the upper gastrointestinal disorder evident in our patient may represent a continuation of this functional disorder into later life.

Cases with deletions extending into band $\mathrm{q} 31$ have had a more variable phenotype with additional features including thumb and fifth finger hypoplasia, ${ }^{67}$ and 
Cases of deletion of bands 13q21 and 13q22.

\begin{tabular}{|c|c|c|c|c|c|}
\hline & This case & $\begin{array}{l}\text { Toomey et al } \\
\quad(\text { case 1) }\end{array}$ & $\begin{array}{l}\text { Toomey et } \mathrm{al}^{3} \\
\text { (case 2) }\end{array}$ & Noel $e t a l^{4}$ & $\begin{array}{c}\text { Tranebjaerg } \\
\text { et al }\end{array}$ \\
\hline Age at reporting & $22 y$ & $7 y 9 \mathrm{mth}$ & $26 y$ & $15 y$ & $11 y$ \\
\hline Low birth weight & + & - & - & $?$ & - \\
\hline Abnormal cry at birth & + & & & & \\
\hline Microcephaly & - & + & + & + & \\
\hline Hypotonia & + & & & + & \\
\hline Developmental delay & + & + & + & + & + \\
\hline Delayed language & + & + & + & + & + \\
\hline Growth retardation & + & + & + & + & + \\
\hline Broad nasal bridge & + & + & + & + & + \\
\hline Dystopia canthorum & + & + & & + & + \\
\hline Low set or posteriorly & & & & & \\
\hline rotated ears & + & + & + & & + \\
\hline Irregular dentition & + & & & - & + \\
\hline Short hands/digits & + & + & & & \\
\hline Brachycephaly & + & + & & & - \\
\hline Strabismus & + & & + & + & \\
\hline Short neck & + & & & & \\
\hline Swallowing difficulties & + & & & & + \\
\hline Prominent nose & + & & & & \\
\hline
\end{tabular}

perineal abnormalities with atrial septal defect in one case. ${ }^{8}$ One early case reported had an atypically mild phenotype. 9

A familial deletion solely of band $\mathrm{q} 21$ has been described associated with a normal phenotype. ${ }^{10}$ The cardinal features of our patient and the others described in the table may therefore be attributable mainly, if not entirely, to deletion of band $\mathrm{q} 22$.

We wish to thank Professor A G M Campbell for referring the family for investigation, and $\mathrm{Dr} A \mathrm{~W}$ Johnston for his support and helpful comments on the manuscript.

1 Niebuhr E. Partial trisomies and deletions of chromosome 13. In: Yunis JJ, ed. New chromosomal syndromes. New York: Academic Press, 1977:273-99.

2 Yunis JJ, Ramsey N. Retinoblastoma and subband deletion of chromosome 13. Am f Dis Child 1978;132:161-3.
3 Toomey KE, Mohandas T, Sparkes RS, Kaback MM, Rimoin DL. Segregation of an insertional chromosome rearrangement in three generations. F Med Genet 1978;15:382-7.

4 Noel B, Quack B, Rethore MD. Partial deletions and trisomies of chromosome 13; mapping of bands associated with particular malformations. Clin Genet 1976;9:593-602.

5 Tranebjaerg $L$, Nielsen KB, Tommerup $N$, Warburg $M$, Mikkelsen M. Interstitial deletion 13q: further delineation of the syndrome by clinical and high-resolution chromosome analysis of five patients. Am $\mathcal{F}$ Med Genet 1988;29:739-53.

6 Pai GS, Thomas GH, Leonard CO, Ward JC, Valle DL, Pyeritz RE. Syndromes due to chromosomal abnormalities: partial trisomy 22, interstitial deletion of the long arm of 13 , and trisomy 8. Johns Hopkins Med f 1979;145:162-9.

7 Roland B, Lowry RB, Robertson AS, Cox DM. An interstitial deletion of the long arm of chromosome 13. Clin Genet 1989;35:276-81.

8 Serena-Lungarotti M, Calabro A, Mariotti G, Mastroiacovo PP, Provenzano S, Dallapiccola B. Interstitial deletion 13q syndromes: a report on two unrelated patients. Hum Genet 1979;52:269-74.

9 Nielsen J, Homma A, Christiansen F, Rasmussen K, SaldanaGarcia P. Deletion long arm 13. Hum Genet 1977;37:339-45.

10 Couturier J, Morichon-Delvallez N, Dutrillaux B. Deletion of band 13q21 is compatible with normal phenotype. Hum Genet 1985;70:87-91. 